\title{
Parenting Characteristics of Families of Adolescents with Bipolar Disorder
}

\author{
Mathew. K.J.1, Vinod Kumar Sinha.2, Deepanjan Bhattacharjee..3, Sakshi Rai.4
}

\section{ABSTRACT:}

Aim: The aim of the study was to examine the parenting characteristics of adolescents with bipolar disorder.

Methods: Parenting style of 30 adolescents with bipolar disorder was assessed and compared with normal group of 30 adolescents. Multidimensional Parenting Scale was used for assessing parenting style.

Results: There were significantly lower levels of love, encouragement, acceptance, progressivism, democratism and higher levels of hate, rejection, autocratism, discouragement, conservatism and dependency found among families' of adolescents with bipolar disorder compared to the normal group.

Conclusion: Results of the present study indicate that there may be such factors related with parenting style which may have a significant role in the onset and course of bipolar disorders in child and adolescent population. Early identification and targeted interventions in these areas might be required for prevention, management, rehabilitation and preventing relapses of children and adolescents with bipolar disorders.

Keywords: Bipolar disorder, parenting, adolescents

\section{INTRODUCTION:}

A family has a most crucial and instrumental role in providing protection as well as nurturing services to the people. It plays a significant role in the healthy growth and development of human beings.

\footnotetext{
${ }^{1}$ Faculty member for Social Work in Mental Health, Dr. Guislain Svastha Education Trust, Ranchi- in collaboration with Tata Institute of Social Sciences (TISS), Mumbai, India.

${ }^{2}$ Professor of Psychiatry, Department of Psychiatry, Central Institute of Psychiatry, Ranchi, India.

${ }^{3}$ Assistant Professor of Psychiatric Social Work, Department of Psychiatric Social Work, Central Institute of Psychiatry, Ranchi, India.

${ }^{4}$ Assistant Professor of Clinical Psychology, Department of Clinical Psychology, Central Institute of Psychiatry, Ranchi, India.

(C) 2015, Mathew K, V Sinha, D Bhattacharjee, S Rai; licensee IJIP. This is an Open Access Research distributed under the terms of the Creative Commons Attribution License (http://creativecommons.org/licenses/by/2.0), which permits unrestricted use, distribution, and reproduction in any Medium, provided the original work is properly cited.
} 
For having a fruitful as well as contended life, every individual has to have an access to good parenting and optimum cares about the significant others especially at their growing age. Good family and parent child relations make healthy children and constitute overall public health. Though the influence of friends gains importance in adolescence, parents still continue to exert their influence in shaping the behaviors and choices of teens. Parent child relationships, parenting style and family functioning have well-documented effects on adolescent health and development (Singh \& Singh, 2001). Studies (O’Leavy et al, 1999; Arrindell et al, 1983) have emphasized the parent, child attachments as a powerful marker variable for later adjustment as well as emotional and behavioral development of the child.

There are well documented evidence which established different associations between parenting style and different mental and behavioral disorders. Maladaptive and affectionless parenting strategies may exaggerate the chances for developing phobic anxiety disorders (Arrindell et al, 1983) and depression (Bryce et al, 2007) among child adolescent population. Low parental nurturing and aversive parental behavior during child rearing may both be associated with elevated risk for offspring personality disorders (Johnson et al, 2006). Parenting practices especially maternal discipline found to be predictive of externalizing behaviour problems of children in later life (Van Zeijl et al, 2007; O'Leary et al, 1999; O'Leary and Vidair 2005; Nix et al, 1999).

Though there are limited evidences the, existing findings regarding the parenting characteristics in child and adolescent bipolar disorders are contradictory. Different studies were used different tools for assessing the parenting styles of children and adolescents with bipolar disorder make it difficult to reach a common conclusion. Though in different measurements a positive association between impaired quality of parenting and bipolar disorders found in some studies (Neeren et al, 2008; Davenport et al, 1979; Geller et al, 2000), a number of studies did not find any significant difference (Joyce, 1984; Parker, 1979; Perris et al, 1986; Cook et al, 1999).

The existing uncertainty and inconsistency regarding the study findings about the parenting characteristics of parents of child and adolescents with bipolar disorders requires more attention and comprehensive assessments. The present study was planned in this context with an aim of examining the parenting characteristics of families of adolescents with bipolar disorder. 


\section{METHOD}

\section{Design, participants and setting}

The present study was a cross sectional hospital based study conducted at the Child and Adolescent Psychiatric Unit of Central Institute of Psychiatry (CIP), Ranchi, India, within a time frame of 2008-2010. The present study included 60 adolescents between the age range of 13 to 18 years, among which 30 were adolescents with bipolar affective disorder and 30 were normal adolescents. A written conscent had been obtained from all the participants. The adolescents with bipolar disorder fulfilling the criteria for bipolar disorder, according to ICD- 10 - DCR (WHO, 1993), staying with the parents at least for the last two years and their families were selected from the Child Psychiatric Unit of Central Institute of Psychiatry, Ranchi by using purposive sampling. The adolescents without bipolar disorder and their families were selected from a school in the nearby locality. The patients with comorbid mental illness, neurological disorders, chronic physical illness, physical disabilities and family history of mental illness among first degree relatives were excluded from the study and the same exclution criteria along with presence of any kind of mental illnesses had been applied to the normal group.

\section{Measures}

A socio-demographic and clinical data sheet was designed for the present study for recording socio-demographic and clinical variables like age of onset, duration of illness, family history and clinical characteristics.

Multidimensional Parenting Scale (Chauhan and Khokhar, 1985) used in the present study for assessing the parenting style of the parents of the subjects. The scale which uses Hindi language, has 56 items measures in the two ends of the seven dichotomous dimensions, namely hate v/s love, discouragement v/s encouragement, rejection v/s acceptance, dependence v/s independence, autocratism v/s democratism, submission v/s dominance and conservation v/s progressivism representing negative and the positive dimensions of parenting. A higher score in the positive domains indicates more desirable parenting and in the negative domains higher score indicates deviant parenting. A score below 40 in positive domains and above 60 in negative domains are given as the cutoff scores. Any one of the parent who are available requested to fill the questionnaire. 
General Health Questionnaire (Goldberg \& Hiller, 1979) was used in the study for screening normal participants and those scored 3 or more were excluded from the study.

\section{Statistical analysis}

The Statistical Package for Social Sciences (SPSS) 13.0 for windows was used for statistical analysis. Descriptive statistics were used for analyzing discrete and continuous variables. Chi square test was used for comparing categorical variables and student t- test for continuous variables.

\section{RESULTS}

Table 1 shows the details of the socio demographic characteristics of the subjects. $66.7 \%$ of the patient group and $60 \%$ of normal group were males with an average age of $15.7 \pm 1.17$ years and 15.2 \pm 1.21 years respectively. The average duration of illness was $3.05 \pm 1.21$ years. Majority of the respondents were from Hindu religion $(86.7 \%$ \& $70 \%)$ with an education of below matriculation level. Most of the respondents were students from rural, low socio-economic families without any family history of psychiatric illness. 


\section{Table 1 - Socio demographic characteristics}

\begin{tabular}{|c|c|c|c|c|c|c|}
\hline \multirow{2}{*}{\multicolumn{2}{|c|}{ Variable }} & \multicolumn{2}{|l|}{ Group } & \multirow[b]{2}{*}{$X^{2 /} t$} & \multirow[b]{2}{*}{ df } & \multirow[b]{2}{*}{$\mathbf{P}$} \\
\hline & & $\begin{array}{l}\text { Patient } \\
\text { N } \quad(\%) / \\
\text { Mean } \pm \text { sd }\end{array}$ & $\begin{array}{l}\text { Normal group } \\
\mathrm{N}(\%) / \\
\text { Mean } \pm \text { sd }\end{array}$ & & & \\
\hline \multicolumn{2}{|l|}{ Age (in years) } & $15.7 \pm 1.17$ & $15.2 \pm 1.21$ & 1.54 & 58 & .128 \\
\hline \multirow[t]{2}{*}{ Sex } & Males & $20(66.7)$ & $18(60)$ & \multirow[t]{2}{*}{.28} & \multirow[t]{2}{*}{1} & \multirow[t]{2}{*}{.395} \\
\hline & Females & $10(33.3)$ & $12(40)$ & & & \\
\hline \multirow[t]{2}{*}{ Religion } & Hindu & $26(86.7)$ & $21(70)$ & \multirow[t]{2}{*}{2.45} & \multirow[t]{2}{*}{1} & \multirow[t]{2}{*}{.105} \\
\hline & Non- Hindu & $4(13.3)$ & $9(30)$ & & & \\
\hline \multirow[t]{2}{*}{ Education } & Below matric & $22(73.3)$ & $23(76.7)$ & \multirow[t]{2}{*}{.08} & \multirow[t]{2}{*}{1} & \multirow[t]{2}{*}{.500} \\
\hline & Matric and above & $8(26.7)$ & $7(23.3)$ & & & \\
\hline \multirow[t]{2}{*}{ Residence } & Rural & $29(96.7)$ & $25(83.3)$ & \multirow[t]{2}{*}{2.96} & \multirow[t]{2}{*}{1} & \multirow[t]{2}{*}{.097} \\
\hline & Urban & $1(3.3)$ & $5(16.7)$ & & & \\
\hline \multirow[t]{2}{*}{ Occupation } & Nil & $3(10)$ & 0 & \multirow[t]{2}{*}{3.15} & \multirow[t]{2}{*}{1} & \multirow[t]{2}{*}{.119} \\
\hline & Students & $27(90)$ & $30(100)$ & & & \\
\hline \multirow[t]{2}{*}{ Family income } & Below Rs. 5000/ & $24(80)$ & $20(66.7)$ & \multirow[t]{2}{*}{1.36} & \multirow[t]{2}{*}{1} & \multirow[t]{2}{*}{.191} \\
\hline & Above Rs.5000/ & $6(20)$ & $10(33.3)$ & & & \\
\hline \multirow[t]{2}{*}{ Diagnosis } & BPAD- M & $29(96.7)$ & & & & \\
\hline & BPAD- DEP & $1(3.3)$ & & & & \\
\hline \multicolumn{2}{|c|}{ Duration of illness (in years) } & $3.0 \pm 1.21$ & & & & \\
\hline \multirow{2}{*}{$\begin{array}{l}\text { Family history of } \\
\text { psychiatric illness }\end{array}$} & Present & $11(36.7)$ & $6(20)$ & \multirow[t]{2}{*}{2.05} & 1 & .126 \\
\hline & Absent & $19(63.3)$ & $24(80)$ & & & \\
\hline
\end{tabular}

Note: BPAD-M: bipolar affective disorder, last episode manic

BPAD-DEP: bipolar affective disorder, last episode depressive 
Table 2 shows details of the results of Multidimensional Parenting Scale. Majority of the families in both groups fall under normal range according to the cutoff scores, but there was a significant difference found in the score ranges between the two groups in many of the sub domains. In positive domains prominent differences found in the in the areas of love $(p<.001)$, encouragement $(\mathrm{p}<.01)$, acceptance, progressivism and democretism $(\mathrm{p}<.05)$. In the negative domains a $\mathrm{p}<.001$ level of significant difference found in the areas of rejection, conservatism and dependency and $\mathrm{p}<.01$ level significant levels of differences were found in the areas of hate, discouragement and autocratism. 
Table 2 Comparison of Results of Multi Dimensional Parenting Scale between patient and normal group

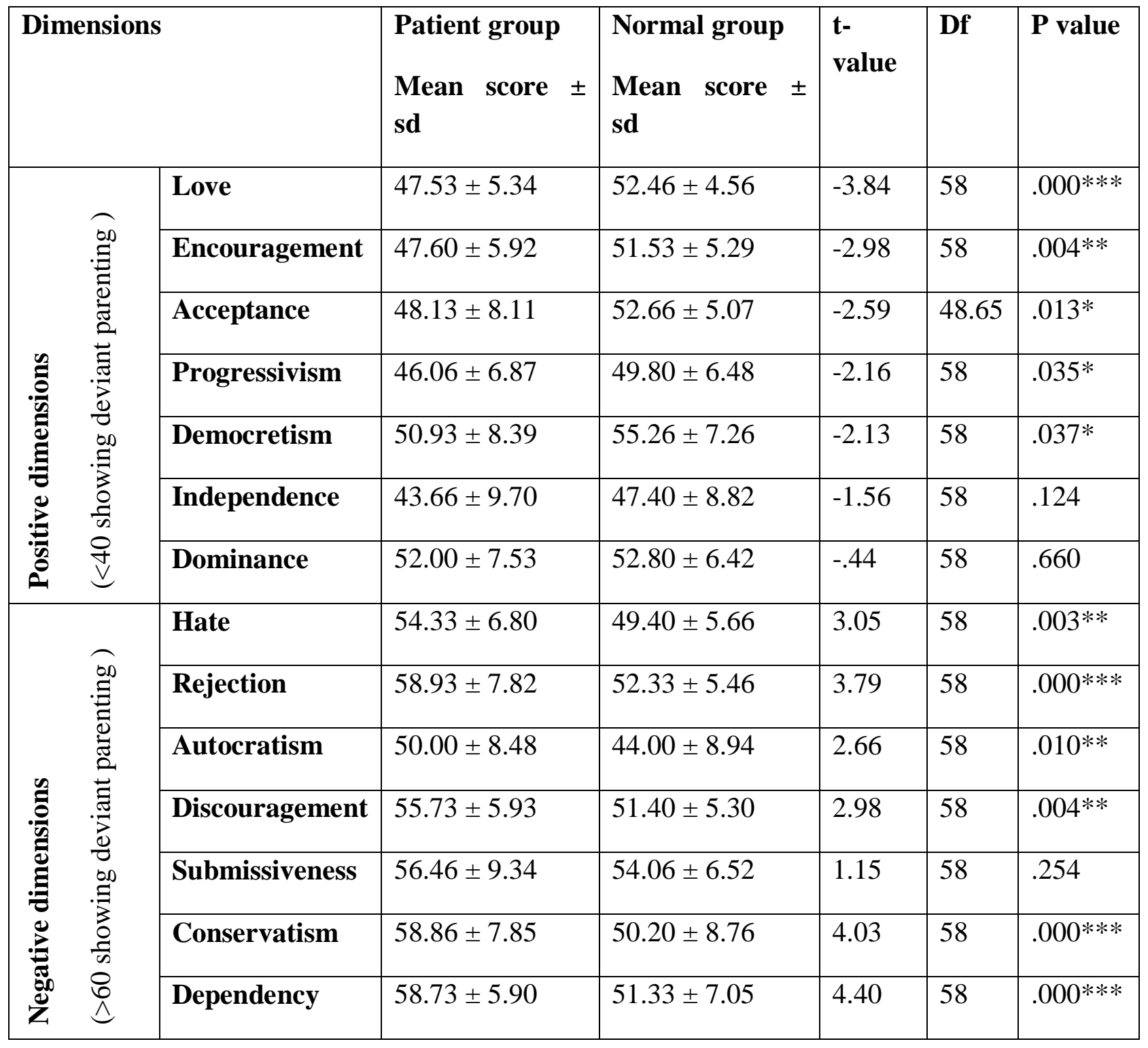

$*$ - significant at .05 level, ** - significant at .01 level, *** - Significant at .001 level 


\section{Parenting Characteristics of Families of Adolescents with Bipolar Disorder}

\section{DISCUSSION}

The current study assessed the parenting style of the parents of 30 adolescent patients with bipolar disorders and the normal group by using the Multidimensional Parenting Scale (Chauhan \& Khokhar, 1985), which is a 56 item self reporting questionnaire in Hindi language. It is the reason for selecting this measurement for the current study, as the majority of the beneficiaries who are attending the child and adolescent unit of Central Institute of Psychiatry are Hindi speaking. It identifies seven qualities for ideal or positive parenting such as love, encouragement, acceptance, independence, democratize, dominance and progressivism. The undesirable characteristics measures by the measurement are hate, discouragement, rejection, dependence, autocratism, submission and conservation. In positive domains, a score below 40 indicates deviant parenting and in negative domains a higher score than 60 indicates deviant parenting on the basis of cutoff scores.

As the Table 2 shows in both of the positive and negative domains, the mean score of both groups was coming under normal functioning on the basis of cutoff scores. But one cannot ignore the fact that there is a big difference between the score ranges of both group. The differences between score range has been suggesting a definite lacking of parental love, encouragement, acceptance, progressivism and democratize for the clinical group in the positive domains. It is clearly indicating that the children with bipolar disorder lacking love and encouragement in significantly greater levels compared to the normal group. It is also evident from Table 2 that the parents of bipolar patients has shown higher levels of hate, rejection, autocratism, discouragement, conservatism and dependency compared to the normal group.

Previous studies also investigated about the relationship of perating and Bipolar disorders in different aspects by using different tools and malfunctioning in multiple domains has beed observed. Lower levels of acceptance, warmth, higher levels of negative psychological control and greater levels of emotional maltreatment from both parents of children with bipolar disorders and greater levels of physical maltreatment by mothers found in an earlier study by Neeren et al (2008). Adverse life events in the forms of maltreatment especially from divorced or separated parents are found to be more common among pediatric Bipolar patients in another study (Marchand et al, 2005). Repetitive maladaptive patterns of avoidance of affect, unrealistic standards of conformity and displaced parental low self-esteem were found among children with bipolar disorders by Davenport et al (1979) in structured interviews. A significantly greater 
impairment on maternal-child warmth, maternal-child and paternal-child tension found among 7-16-year-old patients with bipolar disorders than compared with Attention Deficit Hyperactivity Disorder and normal community controls by Geller et al (2000). Interestingly the only maternal side found to be impaired in the study by Rosenfarb et al (1994), in which bipolar patients reported less maternal affection and attachment with mothers than normal control, but did not differ from controls on paternal affection and attachment.

Though some studies found no significant difference of parental characteristics of bipolar children and a control group (Joyce, 1984; Parker, 1979; Perris et al, 1986; and Cook et al, 1999) many studies found significant problems in terms of deviant parenting among families of children with bipolar affective disorder (Neeren et al, 2008; Davenport et al, 1979; Geller et al, 2000; Rosenfarb et al, 1994). A cumulative exposure to adverse childhood experience including physical abuse, sexual abuse, parental mental illness, loss of parent, parental separation or divorce, witnessing domestic violence, and placement in foster or kinship care were found to be contributed to worse mental and physical health and functional outcomes among adults with severe mood disorders (Lu et al, 2008). The role of uncontrollable childhood stressful events have been emphasized in a study by Grandin et al (2007), whereas the role of genetics has been highlighted by Mortensen et al (2003) than the familial risk factors in relation with the risk of bipolar disorders.

The variations and diffences in the measurements and differences in considering certain level and aspects for defining deviant parenting may be a reason for the differences between different studies. Again the little availability of studies specifically in the area also limiting the scope for a generalized enquiry interms of culture, country, region, social class etc. in relation with parenting style of families of children with bipolar disorders. Although we cannot make a conclusion that the problems relating to parenting are the ultimate cause for the onset of various psychiatric problems, because like in the present study the evaluations have been carried out during the course of the illness in most of the studies. The deveint prenting may be an outcome of illness too. But it is sure that these factors will affect the treatment and aftercare of children with bipolar disorders. Joyce (1984) and Cooke et al (1999) opinioned that family environment and parenting characteristics were associated with the severity and course of the disorder. Hence as a part of the comprehensive management and rehabilitation plan for the children and 
adolescents with bipolar disorders, it is very important to understand the deifits and challenges relating to the parenting style of each individuals as the parents are the only care takers available mostly for the people in the child and adolescent group.

The small sample size of the present study may reduce the generalization of the study findings. It is lacking the representation of all subcategories of bipolar affective disorder, as most of the respondents in the patient group were diagnosed with bipolar affective disorder manic type. The majority of the participants were male in the present study and most of the respondents belonged to low socioeconomic status from rural areas. Due to limited sample frame and lack of time, the socio- demographic variables was not uniform in all areas of the clinical group and normal group. There may be a relationship between the number of episodes, relapses and the study variables, which were not addressed in the present study.

\section{CONCLUSION}

Parent child attachments and parenting style has been widely discussed in significance with various psychiatric disorders. But the relationships between early onset bipolar disorders and parenting style have never been studied adequately. Although the results are contradictory, most of the studies show the importance of parenting style with respect to the early onset bipolar disorders. The results of the present study indicate that there may be such factors related with parenting style which may have a significant role in the onset and course of bipolar disorders in child and adolescent population. Early identification and targeted interventions in these areas might be required for prevention, management, rehabilitation and preventing relapses of bipolar disorders among children and adolescents.

\section{Role of funding source}

Nil

\section{Conflict of interest}

Nil

\section{Acknowledgements}

We thank to all the participants of the current study, and their family members. 


\section{REFERENCE:}

1. Arrindell, W. A., Emmelkamp, P. M. G., Monsma.A., Brilman. E. (1983) The role of perceived parental rearing practices in the aetiology of phobic disorders: a controlled study. British Journal Psychiatry 143:183-187.

2. Bryce, D. M., John, R.W., Jeffrey, J. W. (2007) Examining the association between parenting and childhood depression: A meta-analysis. Clinical Psychology Review 27:986-1003.

3. Chauhan, N. S., \& Khokhar, C. P. (1985) Multi-Dimensional Parenting scale, Published by MAAPA-Publications, Meerut.

4. Cooke, R.G., Young, L.T., Mohri, L., Blake, P., Joffe, R. T. (1999). Family-of-Origin Characteristics in Bipolar Disorder: A Controlled Study. Canadian Journal of Psychiatry, 44, 379-381.

5. Davenport, .B., Adland, M.L., Gold, P.W., Goodwin, F.K. (1979). Manic-depressive illness: Psychodynamic features of multigenerational families. American Journal of Orthopsychiatry. 49(1): 24-35. DOI: 10.1111/j.1939-0025.1979.tb02582.x

6. Geller, B., Bolhofner, K., Craney, J.L., Williams, M., DelBello, M.P., Gundersen, K. (2000) Psychosocial functioning in a prepubertal and early adolescent bipolar disorder phenotype. Journal of American Academy of Child and Adolescent Psychiatry 39:1543-1548.

7. Goldberg, D. P. \& Hiller, V. F. (1979) A scaled version of the general health questionnaire. Psychological Medicine 9:139-145.

8. Grandin, L.D. \& Alloy, L.B. (2007) Childhood stressful life events and bipolar spectrum disorders. Journal of Social and Clinical Psychology, 24(4):460-478.

9. Johnson, C., Cohen, P., Chen, H., Kasen, S., Brook, J.S. (2006) Parenting behaviors associated with risk for offspring personality disorder during adulthood. Achieves of General Psychiatry 63:579-587.

10. Joyce, P.R.(1984).Parental bonding in bipolar affective disorder. Journal of Affective Disorders. 7(3-4):319-24.

11. Lu, W., Mueser, K.T., Rosenberg, S.D., Jankowski, M.K. (2008) Correlates of adverse childhood experiences among adults with severe mood disorders. Psychiatric Services, 59(9):1018-1026

12. Marchand, W.R., Wirth, L., Simon, C. (2005) Adverse life events and pediatric bipolar disorder in a community mental health setting. Community Mental Health Journal, 41(1):67-75. 
13. Mortensen, P.B., Pedersen, C.B., Melbye, M., Mors, O., Ewald, H. (2003) Individual and familial risk factors for bipolar affective disorders in Denmark. Archives of General Psychiatry, 60(12):1209-1215.

14. Neeren. A.M., Alloy, L. B., Abramson, L. Y. (2008). History of parenting and bipolar spectrum disorders. Journal of Social and Clinical Psychology 27: 1021 - 1044.

15. Nix, R.L., Pinderhughes, E.E., Dodge, K.A., Bates, J.E., Pettit, G.S., McFadyenKetchum, S.A. (1999). The relation between mothers' hostile attribution tendencies and children's externalizing behavior problems: the mediating role of mothers' harsh discipline practices. Child Development 70:896-909.

16. O'Leary, S.G. \& Vidair, H.B. (2005) Marital adjustment, child-rearing disagreements, and overreactive parenting: predicting child behavior problems. Journal of Family Psychology $19: 208-216$

17. O'Leary, S.G., Slep, A.M., Reid, M.J. (1999). A longitudinal study of mothers' overreactive discipline and toddlers' externalizing behavior. Journal of Abnormal Child Psychology 27:331-341.

18. Parker, G. (1979) Parental Characteristics in Relation to Depressive Disorders. British Journal of Psychiatry 134: 138-147.

19. Perris, C., Arrindell, E., Van der Ende, J. V., \& Knorr, L. (1986). Perceived depriving parental rearing and depression. British Journal of Psychiatry, 148, 170 - 175

20. Rosenfarb, I.S., Becker, J., Khan, A. (1994) Perceptions of parental and peer attachments by women with mood disorders. Journal of Abnormal Psychology, 103:637-644.

21. Singh, N. N. \& Singh, S. D. (2001) Developmental Considerations in treatment. In Chapter 2, Handbook of Conceptualization and treatment of Child Psychopathology, Pergamon: Elseveir Science. 9- 41.

22. Van Zeijl, J., Mesman, J., Stolk, M. N., Alink, L. R. A., Van IJzendoorn, M. H., Bakermans-Kranenburg, M. J., Juffer, F., Koot, H. M. (2007). Differential susceptibility to discipline: The moderating effect of child temperament on the association between maternal discipline and early childhood externalizing problems. Journal of Family Psychology, 21, 626636. doi: 10.1037/0893-3200.21.4.626

23. World Health Organization (1993) The ICD-10 Classification of Mental and Behavioural Disorders Diagnostic criteria for research. World Health Organization, Geneva. 